\title{
The Effectiveness of Consilience on Teaching Science Supported with Visual Arts in Developing Some Primary Stage Pupils' Visual Thinking Skills and the Attitude towards the Relation between Science and Arts
}

Eman Mohamed Ibrahiem Elhosiny Prof.Dr. Hamdi Abul - Fettouh Otiefa Prof.of Curricula and Science Education Faculty of Education - Mansoura University Ass.Prof. Mohamed Roshdy Abo - Shama Associate Prof. of Curricula and Science EducationFaculty of Education - Mansoura University

\section{Abstract:}

he purpose of this study was to investigate that the
subject of this study was to determine the role of
consilience on teaching science and the educational system in Egypt influenced students' attitudes towards the relation between Science and arts. It has provided insights about the visual thinking skills influence students' visualization of science concept, how visual arts shape students' learning attitudes to increase pupils' academic achievement. The study utilized E.0 Wilson's (1998) aspects to consilience (unity of knowledge) theory, which it is a special form of integration. Primary Stage Pupils' came from homogeneous background in terms of different education systems in Egypt have been participated. The results shows the correlation between achievement and attitudes towards science and arts is equal (0.454), and between attitudes towards science and arts and visual thinking skills is found to be equal (0.408). This research is advocated for consilience on teaching Science supported with Visual Arts to promote visual thinking skills and attitudes towards the relation between science and arts. Implications of the study is science curriculum might be welcome based on the Sci-Visual Art education and supported Science Content with consilience may be presented as a Superior method.

Keywords: Consilience, Attitude, visual thinking skills, Visual Arts, Sci-Visual Art.

\section{Introduction:}

No doubt that nowadays is the technological revolution era in which changes are fast and events are continued in different shapes socially, cognitively and technologically. People who are 
responsible for planning the educational politics have to take care of training others how to accept and predict changes and challenges through developing, required skills and abilities.

According to such trend, it is necessary to get a relationship between different disciplines either in a general field or in subbranches. One of the most important changes in the educational field is to get the overall vision and dealing with each unit in such a vision to progress gradually in knowledge. That is why, It is urgent to own a complete knowledge base through which we can deal with sub-skills in special fields. The specific education tries hard to update such developments through using external suppuration from other fields to simplify pupils, and to join into a unit of knowledge between science and art.

However, there is a relationship between science and art; both fields are different in many directions. They are related to each other but not combined. According to (Bloomfield, 2000) Science concentrate first on knowledge, which could be translated into scientific technology. On the other side art is a creative artificial product that can present things showing beauty, ugliness or unusual vision such as vision cannot be explained without a complete meaningful frame.

Accordingly, Science and art are different basically even that some researchers tried to get sort of advantages for each in a trial to support the relationship between both of them.

In this regard developmental movements rely on the entrance to the integration of science and the arts and indicate the role of the visual arts in the learning and teaching of science emerged results showed that the integration of the different branches of science in science education promotes the development of educated academically, socially, morally and behaviorally and proved that pupils are able to learn and apply the knowledge better when they have Opportunities with the tasks and practical activities depended on the use of visual arts elements.

Consilience as an idea encourages the pooling of knowledge from various disciplines in order to solve problems and improve 
understanding of the way things work. The various disciplines might not wholly agree, but it is not necessary that they do. Rather, argument is that understanding will come through appreciation of the many facets of color revealed by many ways of knowing and through the value of interdisciplinary.

Since 1840 by William Whewell, in his synthesis, The Philosophy of the Inductive Sciences was the first to speak of consilience notably a "jumping together of knowledge" "Consilience is by the making of facts and fact-based theory across disciplines to create a common groundwork of explanation ". The term of consilience is preferable over other terms like; "Coherence" or "interconnectedness" which it has acquired many meanings scattered among the different disciplines. Technically, it means there is agreement of two or more inductions drawn from different sets of datawhereas coherence has several possible meanings. Only one of which is consilience that more serviceable than the words coherence or interconnectedness (Cockell \& etal,2011).

Dore (2016:138) The Concept of consilience was originally coined as the phrase "Consilience of Instructions". It's related to synthesis the philosophy of the inductive Sciences (Wilson, 1999).

(Dhanapal \&etal, 2014) and many studies have shown the effectiveness of the integration of the visual arts in the learning and teaching of other subjects, especially science and mathematics, and in spite of the researchers and those interested found The scarcity of studies dealing views for such a merger on teachers and pupils (Gelineau, 2011).In the context of interest in education and science of psychologists topic of thinking and multiple patterns and development capabilities, both of (Buzan\& Buzan, 2010) referred that visual thinking is one of a thinking patterns that captured the attention of educators in recent years, because of its great importance, the studies have proved that more than $75 \%$ of the knowledge held to human through seeing. 
(Salah, 2012, 13: 54) described the visual system of thinking, is the set of processes that translate Vision of the individual to read visual format and convert the visual language of carried form into language and meaningful written or vocalized context to build on some of his skills in finding unity of knowledge between science and the arts are following:

1. The skill of visual reading: the ability to determine the dimensions and the nature of the presented figure and that's the least visual thinking skills.

2. The Skill of visual interpretation: the ability of forming a visual image ; transform abstract idea into visual form and expressing it (transform visual image into a speech language .

3. The skill of visual Discrimination: the ability to link between form elements and creating relationships. the ability of notice the similarities and differences between forms and some visual samples to select the odd shape or the similar one according to the color, shape direction and size, recognition relation, solving problem as a result of visual motivation.

4. The skill to recognize and interpret the mystery: the ability to clarify the gaps and inaccuracies in the relations and to bring them closer.

5. The skill of extracting meanings: the ability to infer new meanings and come up with scientific concepts and principles.

6. The skill of forming and Establishing : The ability to transform ideas and information into representations of meaningful shapes and graphics.

The attitude is an acquired mental readiness, expressed by the person's judgment to the subject of the attitude, which makes the person ready to respond in a special way, taking a particular position towards the subject of the attitude, leading to the outcome of his behavior towards this subject a certain character that allows some prediction of the individual's response in 
situations related to the subject attitude (Otiefa \& Srour, 2011:284) the ensuing activities, and its role in the life of the individual and society. Attitudes impel people to react to objects, situations or propositions in ways that can be called favorable or unfavorable.

The researcher defines the attitude toward the relation between science and arts : Is the position of student who studied science supported by the arts in the fifth grade of primary stage to find a connection link between science and the arts with acceptance or rejection or neutral when the use of sciences supported by the arts in teaching.

There is a need to adopt a future vision which looks of the different branches of science with an integrative view supported the building unit of knowledge between science and the arts and help acquisition of scientific concepts in an integrative addresses some of the skills of visual thinking to match the students characteristics and increases the interaction and motivation to respond held a better impact on the academic achievement and attitudes towards science and the arts.

\section{Research Questions:}

To what extend does Science supported with visual arts promote Some Primary Stage Pupils' Visual Thinking Skills and their Attitude towards the Relation between Science and Arts?

\section{Methodology:}

\subsection{Participants:}

Fifth grade pupils on Al-Ferdous Experimental language school under the educational administration of Talkha as a sample for the control group \& Fifth grade pupils on Mansoura Royal language schools as a sample for the experimental group.

\subsection{Materials:}

1. Visual thinking skills list in Science for the fifth primary stage pupils'. 
2. Teacher's guide can use for teaching Science supported with arts based on consilience to enhance Visual thinking skills.

3. Student activity booklet for chapter "light" from the book of

Science "Science and You " for primary fifth pupils' using Science supported with arts based on consilience.

\subsection{Tools:}

1. Visual thinking skills test in science supported by visual arts (researcher preparation).

2. Academic achievement test on Science for the fifth primary stage pupils'.

3. A questionnaire towards the relationship between science and the arts.

\subsection{Procedures:}

The current research employed:

- Descriptive and analytical approach: to review the educational literature and previous studies relation to study variables.Visual thinking skills and attitudes towards the relation between science and arts.

- Semi- Experimental approach: in order to determine the effectiveness of using consilience on teaching science supported with arts and enhancing Visual thinking skills in science and attitudes towards the relation between science and arts.

- Procedures of the study: The participants were 24 of fifth grade of primary stage pupils in "Mansoura". There were two classes from different schools So, I selected one of them as a control group and the other is experimental group. Twenty-Four pupils studied science supported with visual arts and the other studied it with usual method. Two groups received pre \& post; visual thinking test, academic achievement test \& a questionnaire towards the relation between science $\&$ arts. It was done on first term of academic year 2017-2018. 


\section{Analysis of Results:}

Table (1): "T" value \& Significant difference between the two studies groups (control - experimental) in visual thinking skills and the overall score for the post test of visual thinking skills.

\begin{tabular}{|c|c|c|c|c|c|c|c|c|}
\hline Visual Skills & group & $\mathbf{N}$ & Mean & \begin{tabular}{|c|} 
Std. \\
Deviation \\
\end{tabular} & $\mathbf{T}$ & Df & sign & eta \\
\hline \multirow{2}{*}{$\begin{array}{c}\text { Visual } \\
\text { Discrimination }\end{array}$} & Exp. & 24 & 11.9167 & 1.01795 & 5.636 & 46 & .000 & 0.41 \\
\hline & Ctrl. & 24 & 10.0000 & 1.31876 & & & & \\
\hline \multirow{2}{*}{$\begin{array}{c}\text { Visual } \\
\text { interpretation }\end{array}$} & Exp. & 24 & 7.0417 & .90790 & 3.292 & 46 & .002 & 0.1 \\
\hline & Ctri. & 24 & 6.0833 & 1.10007 & & & & \\
\hline \multirow{2}{*}{$\begin{array}{c}\text { Extracting } \\
\text { meanings }\end{array}$} & & 24 & 8.6667 & .70196 & 4.944 & 46 & .000 & $\overline{0.35}$ \\
\hline & $\mathrm{Ct}$ & 24 & 6.9167 & 1.58572 & & & & \\
\hline \multirow{2}{*}{$\begin{array}{l}\text { Forming and } \\
\text { Establishing }\end{array}$} & & 24 & 7.9 & .28233 & 2.837 & 46 & .007 & 0.15 \\
\hline & Ctrl. & 24 & 7.29 & 1.04170 & & & & \\
\hline \multirow{2}{*}{ Visual reading } & Exp. & 24 & 6.8750 & .33783 & 2.701 & 46 & .010 & 0.14 \\
\hline & & 24 & 6.16 & 1.23945 & & & & \\
\hline \multirow{2}{*}{$\begin{array}{l}\text { Understanding } \\
\text { and } \\
\text { interpretation } \\
\text { of ambiguity }\end{array}$} & Exp. & 24 & 8.9583 & .99909 & 5.281 & 46 & .000 & 0.38 \\
\hline & Ctrl. & 24 & 6.7917 & 1.74404 & & & & \\
\hline \multirow{2}{*}{ Total } & Exp. & 24 & 51.3750 & 2.06023 & 7.926 & 46 & .000 & 0.58 \\
\hline & Ctrl. & 24 & 43.2500 & 4.58020 & & & & \\
\hline
\end{tabular}

Table (1) shows that, there are statistically significant differences between the mean scores of the control group and the experimental group in the visual thinking skills test and the values of $(\mathrm{t})$ were significant level of 0.05 in favor of the experimental group.

Table (2): "T" value \& Significant difference between the two studies groups (control - experimental) in visual thinking skills and

the overall score for the post of achievement test on science.

\begin{tabular}{|c|c|c|c|c|c|c|c|c|}
\hline & group & $\mathrm{N}$ & Mean & Std. Deviation & $\mathrm{t}$ & $\mathrm{Df}$ & sign & eta \\
\hline \multirow{2}{*}{ Knowledge } & Post.exp & 24 & 12.7083 & 1.23285 & 2.408 & 46 & .020 & 0.11 \\
\cline { 2 - 10 } & Post.ctrl & 24 & 11.5000 & 2.12644 & & & & \\
\hline \multirow{2}{*}{ Comprehension } & Post.exp & 24 & 10.7083 & 1.16018 & 2.188 & 46 & .034 & 0.09 \\
\cline { 2 - 10 } & Post.ctrl & 24 & 9.8333 & 1.57885 & & & & \\
\hline \multirow{2}{*}{ Application } & Post.exp & 24 & 6.6250 & .57578 & 2.849 & 46 & .007 & 0.15 \\
\cline { 2 - 10 } & Post.ctrl & 24 & 5.8750 & 1.15392 & & & & \\
\hline \multirow{2}{*}{ analysis } & Post.exp & 24 & 4.5833 & .71728 & 2.119 & 46 & .040 & 0.09 \\
\cline { 2 - 10 } & Post.ctrl & 24 & 4.0000 & 1.14208 & & & & \\
\hline \multirow{2}{*}{ synthesis } & Post.exp & 24 & 1.9167 & .28233 & 2.828 & 46 & .007 & 0.15 \\
\cline { 2 - 10 } & Post.ctrl & 24 & 1.5833 & .50361 & & & & \\
\hline \multirow{2}{*}{ Evaluation } & Post.exp & 24 & 2.8333 & .38069 & 3.273 & 46 & .002 & 0.19 \\
\cline { 2 - 9 } & Post.ctrl & 24 & 2.0417 & 1.12208 & & & & \\
\hline \multirow{2}{*}{ total } & Post.exp & 24 & 39.3750 & 2.10202 & 3.288 & 46 & .002 & 0.19 \\
\cline { 2 - 9 } & Post.ctrl & 24 & 34.8333 & 6.43135 & & & & \\
\hline
\end{tabular}


The total degree of (T) on the achievement test (3.288) \& it is a statistically significant value at level Significance (0.05) in favor of the post application of the experimental group and corresponds to the effect size of $(0.19)$

Therefore, the variance of the dependent variable due to the effect of the independent variable is $19 \%$ considered to have a significant effect.

Table (3) : The mean scores of the experimental group and the control group in the post-application of Attitude towards the Relation between Science and Arts.

\begin{tabular}{|c|c|c|c|c|c|c|c|c|}
\hline Dimension & group & $\mathbf{N}$ & Mean & $\begin{array}{c}\text { Std. } \\
\text { Deviation }\end{array}$ & t & df & sign & \\
\hline \multirow{2}{*}{$\begin{array}{c}\text { Adoption of Scientific - } \\
\text { Artistic Attitude }\end{array}$} & Exp. & 24 & 13.4167 & .82970 & 2.383 & 46 & .021 & 0.1 \\
\hline & Ctrl. & 24 & 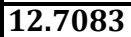 & 1.19707 & & & & \\
\hline \multirow{2}{*}{$\begin{array}{l}\text { Social and Communication } \\
\text { implication of Science } \\
\text { Supported with Visual arts }\end{array}$} & Exp. & 24 & 11.2083 & .88363 & 2.896 & 46 & .006 & \\
\hline & Ctrl. & 24 & 10.2500 & 1.35935 & & & & \\
\hline \multirow{2}{*}{$\begin{array}{l}\text { Attitudes Towards Subject of } \\
\text { Science supported with Arts }\end{array}$} & Exp. & 24 & 29.2917 & 2.27423 & 5.278 & 46 & .000 & \\
\hline & Ctrl. & 24 & 24.4 & 3.86713 & & & & \\
\hline \multirow{2}{*}{$\begin{array}{c}\text { Attitudes towards Science } \\
\text { and Scientists }\end{array}$} & Exp. & 24 & $\begin{array}{l}.3750 \\
\end{array}$ & .82423 & 2.335 & 46 & .024 & 0.1 \\
\hline & Ctrl. & 24 & 6.5833 & 1.44212 & & & & \\
\hline \multirow{2}{*}{$\begin{array}{l}\text { Attitudes towards Art and } \\
\text { Artists }\end{array}$} & Exp. & 24 & 7.5000 & .97802 & 2.308 & 46 & .026 & 0.1 \\
\hline & Ctrl. & 24 & 6.7083 & 1.36666 & & & & \\
\hline \multirow{2}{*}{$\begin{array}{l}\text { Attitudes towards Sci-Art } \\
\text { teacher }\end{array}$} & Exp. & 24 & 11.5833 & .77553 & 2.356 & 46 & .023 & 0.1 \\
\hline & Ctrl. & $\overline{24}$ & 11.0000 & .93250 & & & & \\
\hline \multirow{2}{*}{ total } & Exp. & 24 & \begin{tabular}{|l|}
$\mathbf{8 0} .3750$ \\
\end{tabular} & 3.49922 & 4.698 & 46 & .000 & 0.3 \\
\hline & Ctrl. & 24 & $\begin{array}{l}1.7083 \\
\end{array}$ & 8.33264 & & & & \\
\hline
\end{tabular}

According to the results shown in table (3), there are statistically significant differences between the mean scores of the control group and the experimental group in all dimensions and total score of the questionnaire of attitudes towards the relation between science and arts.

The effect size of consilience on developing attitudes towards the relation between science and arts was (0.32).That means the variance of the dependent variable due to the effect of the independent variable is $32 \%$ that is considered to have a significant effect.

\section{Discussion:}

The effectiveness of consilience on teaching science supported with visual arts in developing some visual thinking skills may refer to 
- Using activities that stimulate thinking of students and facilitate the development of visual thinking.

- Consilience strategy provide an positive environment of sharing points of views freely.

- Introduce visualized questions allow students to think, and help to enlighten their mental excitement.

- The performance of scientific experiments and projects is indispensable when using a variety of activities of science supported of visual arts.

- Through science activities supported with visual arts, students learn to observe, visualize, manipulate materials, and develop the creative confidence to imagine new possibilities. These skills and competencies are also essential to visualization the content.

- The necessary to assess the content of science supported with arts with PBL as consilience emphasize Process.Using "road map for thinking" with classes on this research, have found that it forces students to slow down. Students study science supported with visual art understand that there is not just one answer to a question and that searching for an answer, or the process itself, is important. By grappling with creative problems, students develop habits of mind such as persevering and trial-anderror problem solving.

- Using science supported with visual arts presented art as a natural and sequential in the belief that experiences help pupils to mentally organize thoughts from nondescriptive to recognizable figures.

- Pupils doing higher level of cognitive thinking. Genuine conversation and discussion about topic, a welcome and safe classroom environment with a "Real world-learning and connections".

- Pupils attached a great importance to "subject of science supported with arts" in the development of the individual's creative potentials, in the raising of students' 
motivation for studying, in encouraging the understanding of different social cultures, in the development of personal and collective identities, and the development of interdisciplinary knowledge, skills and competences.

- Pupils are encouraged to talk about their perspective of life as independent \&critical thinkers.

- Using science supported with visual arts helped to develop pupils 'emotions and their perservance necessary to be succeed.

- The focus on the pupils allows them to have an authentic learning experience, giving them a sense of freedom with subjects as well as learning valuable working habits, such as taking risks, planning, and discussing information.

- Using images of visual arts relies on student selfmotivation; reflection awareness, take ownership as well as communicate effectively with their fellow classmates in a constructive manner.

Table (4): Correlation coefficients between experimental group scores in the post application of the three tools

\begin{tabular}{|c|c|c|}
\hline variables & attitude & Visual \\
\hline Achievement & $.454^{*}$ & $\mathbf{. 4 8 3}^{*}$ \\
\hline Attitude & - & $\mathbf{4 0 8}^{*}$ \\
\hline
\end{tabular}

From the previous table, There is no statistically significant difference at the level $(0.05=\alpha)$.The correlation between achievement and attitudes towards science and arts is equal $(0.454)$, the correlation between achievement and visual thinking skills is equal (0.483), and the correlation between attitudes towards science and arts and visual thinking skills is found to be equal (0.408).

\section{Conclusions \& Pedagogical Implications:}

Using consilience was effective in developing primary school pupils' visual thinking skills. The pupils improved their ability to construct mental images, understand, ultimately to think, communicate, create a context, providing an interpretation of their visual experience, recognize visual patterns, exploring, solving picture and sorting information. In addition to that, 
pupils analyzed all kinds of visual images, study of the meanings of visual signs in images as opposed to verbal thinking and getting more capacity to extract meaning from visual images. Pupils directs \&express their thoughts by shapes and lines to take a vague idea \& make the image inclusive rather than exclusive. Pupils had the ability to visualize their thinking. This study recalls for Consilience on teaching supported with visual arts as a promoted long-term meaningful learning, which is evolved on pupils' rehearsal through discussion of images, bridges the gap between the new information and knowledge to be stored with connection of unity of knowledge, organization, elaboration and visual imagery.

\section{References:}

Bloomfield, A. (2000). Teaching Integrated Arts in the Primary School. London: David Fulton Publishers.

Buzan, B. \& Buzan, T. (2010). The Mind Map Book (Mind Set). AlRiyad, Traslated ; Gareer library. (Reference in Arabic)

Cockell, M. , Billotte, J. \& Darbellay, F. (2011).Common Knowledge: The Challenge of Transdisciplinarity. EPFL Press.

Dhanapal, S., Kanapathy, R. \& Mastan, J. (2014). A study to understand the role of visual arts in the teaching and learning of science, Issue 2. Asia-Pacific Forum, Science Learning and Teaching Journal. 15(12).

Gelineau, R. P. (2011). Integrating the Arts across the Elementary School Curriculum. United States of America: Wadsworth, Cengage Learning.

Otiefa, H. A. \& Srour, A. A. (2011).Teaching science in terms of quality education objectives and strategies. 1st Ed, Cairo, Publishing House of Universities, P.284. (Reference in Arabic)

Saleh, S. M. (2012). Evaluation of the content of science books in the preparatory stage in the light of the skills of visual thinking and the extent of student acquisition. Journal of Arab Studies in Education and Psychology, 31(3). (Reference in Arabic)

Wilson, E. O. (1999). Consilience Unity of Knowledge. New York, Division of Random house, Vintage books. 
